\title{
A STUDY OF SEASONAL VARIATION OBSERVED IN OCCURRENCE OF IMMINENT ECLAMPSIA AND ECLAMPSIA AT TERTIARY CARE HOSPITAL
}

\author{
Ashutosh Bahulekar'1, Sonal Phadtare2, R. P. Patange ${ }^{3}$
}

${ }_{1}^{1}$ Lecturer, Department of Obstetrics and Gynaecology, Krishna Institute of Medical Sciences, Karad, Maharashtra.

${ }^{2}$ Senior Resident, Department of Obstetrics and Gynaecology, Krishna Institute of Medical Sciences, Karad, Maharashtra. ${ }^{3}$ HOD, Department of Obstetrics and Gynaecology, Krishna Institute of Medical Sciences, Karad, Maharashtra.

ABSTRACT
BACKGROUND
Eclampsia is an occurrence of seizures in women with pre-eclampsia. It is a leading cause of maternal mortality and morbidity in
India. Their etiology is poorly understood even today. Seasonal variation is considered as one of the cause.

AIMS AND OBJECTIVES

To see the frequency of occurrence of imminent eclampsia and eclampsia during rainy (June to August) and winter (October to December) season.

\section{MATERIALS AND METHOD}

This is a descriptive, retrospective, observational and analytical study on seasonal variations in admission of imminent ecla mpsia and eclampsia patients in Department of Obstetrics and Gynaecology in KIMS, Karad, from 2012 to 2014.

\section{RESULT}

Among 9122 total number of admissions in Department of Obstetrics and Gynaecology 7678 got delivered in our institute. In which 4150 deliveries occurred in rainy season in which imminent eclampsia were $55(1.3 \%)$, eclampsia cases were $42(1.01 \%)$. While 3528 cases delivered in winter in which imminent eclampsia were $28(0.7 \%)$ and eclampsia were $24(0.68 \%)$. The study showed frequency of imminent eclampsia and eclampsia being more common in rainy season than that of winter season.

\section{CONCLUSION}

In our study, we observed the seasonal variation in occurrence of imminent eclampsia and eclampsia. Number of cases of both imminent eclampsia and eclampsia was more common in rainy season. Regular health checkup, availability of health facilities and prompt referral to tertiary hospital can decrease mortality and morbidity of patient.

\section{KEYWORDS}

Pre-Eclampsia, Imminent Eclampsia, Eclampsia, Seizure.

HOW TO CITE THIS ARTICLE: Bahulekar A, Phadtare S, Patange RP. A study of seasonal variation observed in occurrence of imminent eclampsia and eclampsia at tertiary care hospital. J. Evolution Med. Dent. Sci. 2016;5(12):520-522,

DOI: $10.14260 /$ jemds/2016/119

\section{INTRODUCTION}

Imminent eclampsia showed signs of headache, vomiting, epigastric pain, blurring of vision along with raised blood pressure and proteinurea. Eclampsia is a pregnancy specific disease characterised by convulsion associated with preeclampsia. Sometimes it may progress to multi-organ disease. It is defined as occurrence of seizures in women with preeclampsia. Eclampsia remains one of the leading causes of maternal and perinatal morbidity and mortality. More than 63,000 women die every year because of severe pre-eclampsia and eclampsia. All patients with imminent eclampsia and eclampsia were monitored closely, essential diagnostic investigations were done. Treated with magnesium sulphate and delivered soon possible.

Financial or Other, Competing Interest: None.

Submission 15-12-2015, Peer Review 21-01-2016,

Acceptance 27-01-2016, Published 10-02-2016.

Corresponding Author:

Dr. Ashutosh Bahulekar,

Lecturer, Department of Obstetrics and Gynaecology,

Krishna Institute of Medical Sciences,

Karad, Maharashtra.

E-mail: rdashu@gmail.com

DOI: $10.14260 /$ jemds/2016/119
Number of studies suggest correlation of temperature and humidity with occurrence of eclampsia. Only one or two studies show no correlation between weather and occurrence of imminent eclampsia and eclampsia.[1,2] Many studies are conducted showing association of eclampsia with cooler temperature, increased humidity and rainfall.[3,4,5] Majority of study shows incidence of eclampsia is more in winter. $[6,7,8,9]$ However, Tan et al. study suggested incidence of eclampsia more in summer.[10] In our study, we tend to show if there is any association between occurrence of eclampsia and seasonal variation in our institute. Here climate is very unique, which is stable all over the year except for heavy rainfall in monsoon. We are trying to assist association of occurrence of imminent eclampsia and eclampsia with this unique climate. India being country with wide range of variability in weather gives us opportunity to study association of different climatic conditions with that of occurrence of imminent eclampsia and eclampsia.

The purpose of the study is to report frequency of eclampsia according to seasonal variation.

\section{MATERIALS AND METHOD}

This was descriptive, retrospective, observational, analytical and non-interventional type of study. This study was 
conducted in Department of Obstetrics and Gynaecology of Krishna Institute of Medical Sciences University, Karad, during period of 6 months (June, July, August, October, November, December) of each year for 3 successive years from 2012 to 2014. All the patients admitted with imminent eclampsia and eclampsia were included in the study, of all the reproductive age group and parity with more than 20 weeks of gestation, giving history of headache, nausea, vomiting, epigastric pain, raised blood pressure, proteinuria, edema and convulsion were studied. All patients with eclampsia were included in this study and diagnosis was confirmed with history and clinical findings. Inclusion criteria were all patients with hypertension, proteinurea, c/o headache, epigastric pain, blurring of vision, fits during pregnancy, labour or postpartum (within 7 days of delivery). Patients with other convulsive disorders or history of fits other than eclampsia and more than 7 days of post-partum cases were excluded from study.

On admission detailed history was taken, laboratory investigations were done and specific findings were noted.

Data were collected, studied according to season; rainy (June, July and August) and winter (October, November and December); then analyzed.

\begin{tabular}{|c|c|c|c|c|c|c|}
\hline \multirow{2}{*}{ Year } & \multicolumn{3}{|c|}{$\begin{array}{c}\text { Rainy Season } \\
\text { (June, July, August) }\end{array}$} & \multicolumn{3}{c|}{$\begin{array}{c}\text { Winter Season } \\
\text { (October, November, December) }\end{array}$} \\
\cline { 2 - 7 } & No. Deliveries & Eclampsia Cases & $\mathbf{\%}$ & No. Deliveries & Eclampsia Cases & \% \\
\hline 2012 & 1219 & 21 & & 1241 & 13 & \\
\hline 2013 & 1860 & 13 & & 1560 & 4 & 7 \\
\hline 2014 & 1071 & 8 & & 1445 & $\mathbf{2 4}$ & $\mathbf{0 . 6 8}$ \\
\hline Total & $\mathbf{4 1 5 0}$ & $\mathbf{4 2}$ & $\mathbf{1 . 0 1}$ & $\mathbf{3 5 2 8}$ & \multicolumn{1}{c|}{} \\
\hline \multicolumn{7}{|c|}{ Table 1: Seasonal variations noted in eclampsia cases } \\
\hline
\end{tabular}

\begin{tabular}{|c|c|c|c|c|c|c|}
\hline \multirow{2}{*}{ Year } & \multicolumn{3}{|c|}{$\begin{array}{c}\text { Rainy Season } \\
\text { (June, July, August) }\end{array}$} & \multicolumn{2}{c|}{$\begin{array}{c}\text { Winter Season } \\
\text { (October, November, December) }\end{array}$} \\
\cline { 2 - 7 } & No. Deliveries & Imminent Eclampsia Cases & \% & No. Deliveries & Imminent Eclampsia Cases & \% \\
\hline 2012 & 1219 & 22 & & 1241 & 8 & 10 \\
\hline 2013 & 1860 & 22 & & 1560 & 10 & $\mathbf{2 8}$ \\
\hline 2014 & 1071 & 11 & & 1445 & $\mathbf{3 5 2 8}$ & $\mathbf{2 8}$ \\
\hline Total & $\mathbf{4 1 5 0}$ & $\mathbf{5 5}$ & $\mathbf{1 . 3}$ & $\mathbf{3 5}$ & \\
\hline \multicolumn{6}{|c|}{ Table 2: Seasonal variations noted in imminent eclampsia cases } \\
\hline
\end{tabular}

\begin{tabular}{|c|c|c|c|c|c|}
\hline Age & $\mathbf{2 0 1 2}$ & $\mathbf{2 0 1 3}$ & $\mathbf{2 0 1 4}$ & Total number of patients & Percentage \\
\hline $17-20$ & 13 & 10 & 9 & 62 & 21.4 \\
\hline $21-24$ & 26 & 22 & 19 & 67 & 17.9 \\
\hline $25-28$ & 13 & 7 & 6 & 26 & 14.0 \\
\hline $29-32$ & 10 & 6 & 5 & 3 & 2.01 \\
\hline$>33$ & 1 & 2 & 0 & $\mathbf{1 4 9}$ & \\
\hline Total & $\mathbf{6 3}$ & $\mathbf{4 7}$ & $\mathbf{3 9}$ & Table 3: Age and year wise cases of Imminent Eclampsia and Eclampsia \\
\hline \multicolumn{7}{|c}{}
\end{tabular}

\section{RESULT}

Study period of 6 months (June, July, August, October, November, December) of each year for 3 successive years from 2012 to 2014 . Therefore, study period is about 18 months of three consecutive years. Among 9122 admissions 7678 got delivered in our institute, in which 4150 deliveries occurred in rainy season. In rainy season cases of imminent eclampsia were $55(1.3 \%)$ and of eclampsia were 42 (1.01\%), while 3528 delivered in winter season. In winter, cases of imminent eclampsia were $28(0.7 \%)$ and that of eclampsia were 24 (0.68\%) (Table No. 1 and 2).

This study also showed that the factors like age group may influence the causes of imminent eclampsia and eclampsia. Most common affected age group was 21-24 years that was $44.9 \%$ (Table No. 3 ).

\section{DISCUSSION}

Pre-eclampsia was defined as rise in blood pressure (Systolic blood pressure $\geq 140 \mathrm{mmHg}$ or diastolic blood pressure $\geq 90$ $\mathrm{mmHg}$ in previously normotensive women) and proteinurea after 20 weeks of gestation. Imminent eclampsia showed signs of headache, vomiting, epigastric pain, blurring of vision along with raised blood pressure and proteinurea. Eclampsia was diagnosed by presence of seizures in addition to preeclampsia, in absence of any other cause for seizures. All patients with imminent eclampsia and eclampsia were monitored closely, essential diagnostic investigations were done, treated with magnesium sulphate and delivered soon possible.

Among 9122 total number of admissions in Department of Obstetrics and Gynaecology, 7678 got delivered in our institute, in which 4150 deliveries occurred in rainy season in which imminent eclampsia were $55(1.3 \%)$, eclampsia cases were $42(1.01 \%)$. While 3528 cases delivered in winter in which imminent eclampsia were $28(0.7 \%)$ and eclampsia were $24(0.68 \%)$. The study showed frequency of imminent eclampsia and eclampsia being more common in rainy season than that of winter season.

Our study showed significant increase in occurrence of imminent eclampsia and eclampsia in rainy season. Lower 
temperature, humidity and rainfall were related to trigger seizures. This is similar to other studies associating eclampsia with lower temperature.[3,4,5]

Dry climate leads to insensible fluid loss from body.[6] Dehydration protects brain from convulsion.[7] which plays protective role in eclampsia. Monsoon season has direct effect on body fluid volume, but mechanism behind is not still proved. $[8]$

Over hydration and hyponatremia is one of the triggering factors for seizures.[9,10] There is swelling of neurons due to hyponatremia leading to influx of fluids in the neurons, which makes them more fragile, thus increase in frequency of seizures.[5] Chakrapani and Colleagues confirmed incidence of hyponatremia is high in hospitalized patients in months of June to August (Rainy season).[8] Lower temperature, heavy rainfall and humidity were linked to Eclampsia.[9]

Our study showed association of seasonal variation in occurrence of imminent eclampsia and eclampsia. Frequency of imminent eclampsia and eclampsia being more in rainy season (June to August) than that of in winter (October to December). But the exact pathophysiologic mechanism for its occurrence is beyond our scope of study. Further evaluation is needed.

According to the study majority of cases with imminent eclampsia and eclampsia were documented within age group of 21 yrs-24 yrs (44.9\%) (Table No. 3).

\section{ACKNOWLEDGEMENT}

The authors are thankful to Obstetrics and Gynaecology, Department of Krishna Institute of Medical Sciences, Karad, for allowing us to conduct this study. Special thanks to Dr.
Manisha Laddad, Dr. Vidya Aher for their support for paper presentation.

\section{REFERENCES}

1. Alderman BW, Boyko EJ, Loy GL, et al. Weather and occurrence of eclampsia. Int J Epidemiol 1988;17(3):582-8. doi:10.1093/ije/17.3.582.

2. Magann EF, Perry KG, Morrison JC, et al. Climatic factors and preeclampsia related hypertensive disorders of pregnancy. Am J Obstet Gynecol 1995;172(1):204-5.

3. Neela J, Raman L. Seasonal trends in the occurrence of eclampsia. Natl Med J India 1993;6(1):17-18.

4. Neutra R. Meteorological factors and eclampsia. J Obstet Gynecol Br Commonw 1974;81(11):833-840.

5. Agobe JT, Good W, Hancock KW. Meteorological relations of eclampsia in Lagos, Nigeria. Br J Obstet Gynaecol 1981;88(7):706-10.

6. Kambal A. Evaporative water loss in adult surgical patients in the Sudan. Br J Surg 1978;65(2):128-30.

7. Bitterman N, Skapa E, Gutterman A. Starvation and dehydration attenuate CNS oxygen toxicity in rats. Brain Res 1997 June;761(1);146-50.

8. Chakrapani M, Shenoy D, Pillai A. Seasonal variation in the incidence of hyponatremia. J Assoc Physicians India 2002;50:559-62.

9. Subramaniam V. Seasonal variation in the incidence of pre-eclampsia and eclampsia in tropical climatic conditions. 2007;7(18). doi: 10.1186/1472-6874-7-18.

10. Andrew RD. Seizure and acute osmotic change: clinical and neurophysiological aspects. J Neural Sci 1991;101(1):7-18. 